\title{
ТОРАКАЛЬНЫЙ АКТИНОМИКОЗ (ОБЗОР)
}

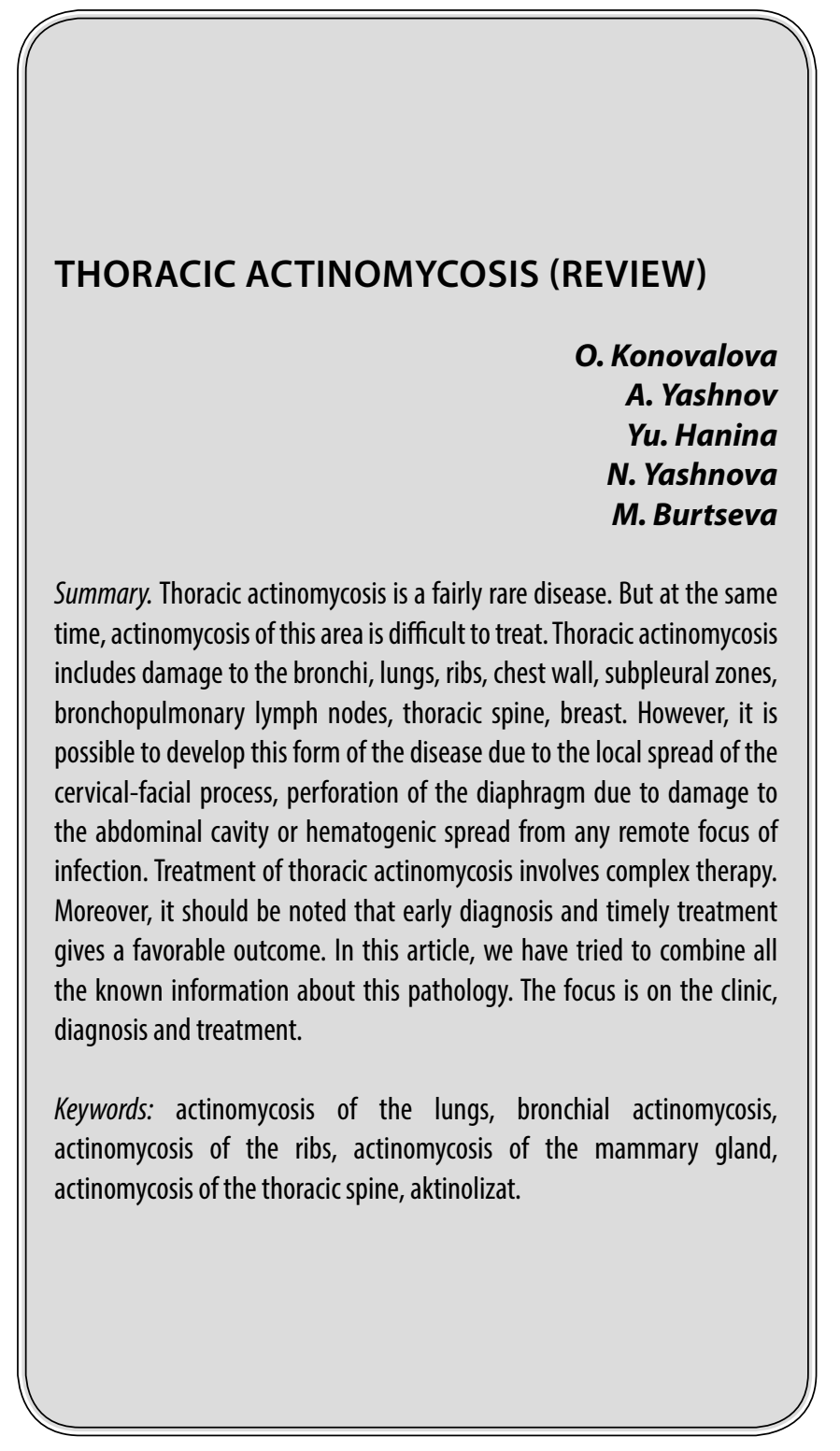

$\mathbf{T}$ оракальный актиномикоз включает в себя поражение бронхов, легких, ребер, грудной стенки, субплевральных зон, бронхопульмональных лимфоузлов, грудного отдела позвоночника, молочной железы и встречаются примерно в 1,3\% случаев.

Причиной развития данного поражения чаще всего является аспирация патогенного материала из ротовой полости, в виде зубного налета, зубного конкремента, содержимого крипты миндалины и т.д. Вместе с тем возможно развитее данной формы заболевания вследствие локального распространения шейно-лицевого процесса, перфорации диафрагмы из-за повреждения

\author{
Коновалова Ольга Геннадьевна \\ ФГБОУ ВО Читинская государственная медицинская \\ академия \\ Яшнов Алексей Александрович \\ ФГБОУ ВО Читинская государственная медицинская \\ академия \\ alexyashnov@mail.ru \\ Ханина Юлия Сергеевна \\ ФГБОУ ВО Читинская государственная медицинская \\ академия \\ Яшнова Надежда Борисовна \\ ФГБОУ ВО Читинская государственная медичинская \\ академия \\ Буриева Мария Александровна \\ ФГБОУ ВО Читинская государственная медицинская \\ академия
}

Аннотация. Торакальный актиномикоз довольно редкое заболевание. Но вместе с тем актиномикоз данной области трудно поддается лечению. Торакальный актиномикоз включает в себя поражение бронхов, легких, ребер, грудной стенки, субплевральных зон, бронхопульмональных лимфоузлов, грудного отдела позвоночника, молочной железы. Вместе с тем возможно развитее данной формы заболевания вследствие локального распространения шейно-лицевого процесса, перфорации диафрагмы изза повреждения брюшной полости или гематогенным распространением из любого отдаленного очага инфекции. Лечение торакального актиномикоза предполагает комплексную терапию. Причем необходимо отметить, что ранняя диагностика и своевременно начатое лечение дает благоприятный исход. В данной статье мы постарались объединить все известные сведенья 06 этой патологии. Прицельно уделяется внимание клинике, диагностике и лечению.

Ключевые слова: актиномикоз легких, актиномикоз бронхов, актиномикоз ребер, актиномикоз молочной железы, актиномикоз грудного отдела позвоночника, актинолизат.

брюшной полости или гематогенным распространением из любого отдаленного очага инфекции.

В легкие, грибок чаще всего заносится током крови, такой вид попадания инфекции носит название - милиарное обсеменение. Согласно статистике, ткани легкого повреждаются у одного из шести пациентов. Для сапрофитов свойственно метастазирование по кровеносным сосудам.

Торакальный актиномикоз может проявляться клинической картиной катарального или гнойного бронхита, бронхопневмонии, абсцесса легкого, плеврита, 


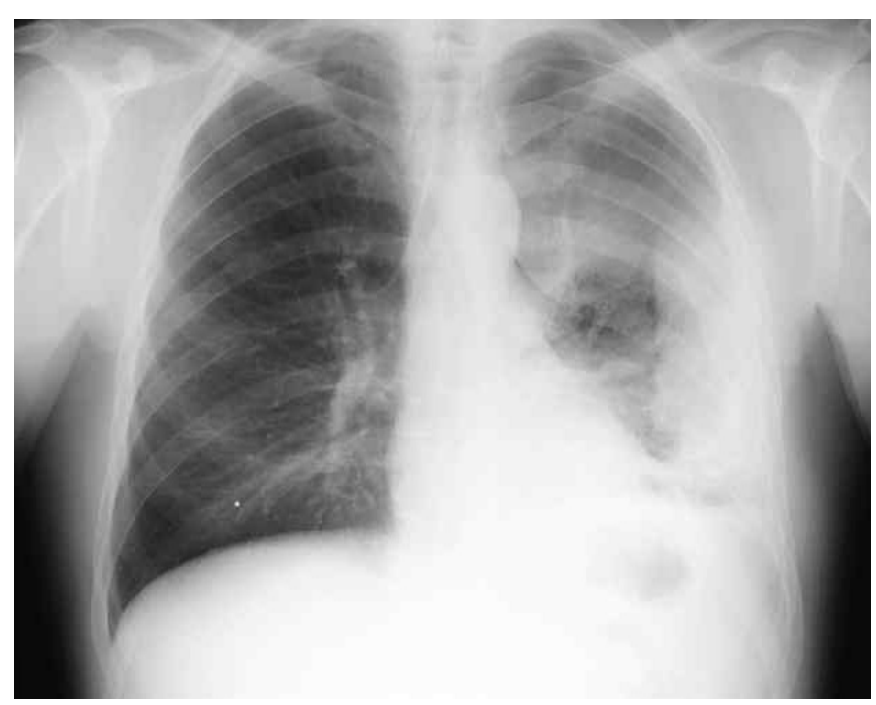

Рис. 1. Рентгенография. Торакальный актиномикоз

остеомиелита ребер, а также выглядеть как опухоль средостения или бронхопневмонический инфильтрат.

Клинически торакальный актиномикоз начинает проявляться кашлем, при котором происходит скудное отделение слизистой или слизисто-гнойной мокроты. Далее присоединяется кровохарканье, одышка, количество выделяемой мокроты растет, повышается температура тела, отмечается обильное потоотделение, появляется боль при вдохе в грудной клетке, происходит формирование в области грудной стенки инфильтрата, возможно с участками абсцедирования, или свищей с гнойно-геморрагическим отделяемым.

Втягивание в патологический процесс плевры вызывает у пациента выраженный болевой синдром. Далее наблюдается поражение стенки грудной клетки. Актиномикоз часто проявляется образованием под кожей инфильтратов сине-багрового цвета, довольно плотных, размягчающихся с возникновением гноящихся свищей, а также разрушением ребер.

При поражении актиномицетами бронхов, появляется изнурительный кашель с отделением мокроты, поднимается температура тела до фибрильных цифр, присоединяются колюще боли в грудной клетке.

При развитии актиномикотического трахеита клиническая картина пациенты жалуются на затруднение дыхания и одышку. При обследовании отмечается уменьшением просвета и деформация трахеи. Гранулематозный актиномикотический процесс может распространяться на мягкие ткани шеи.

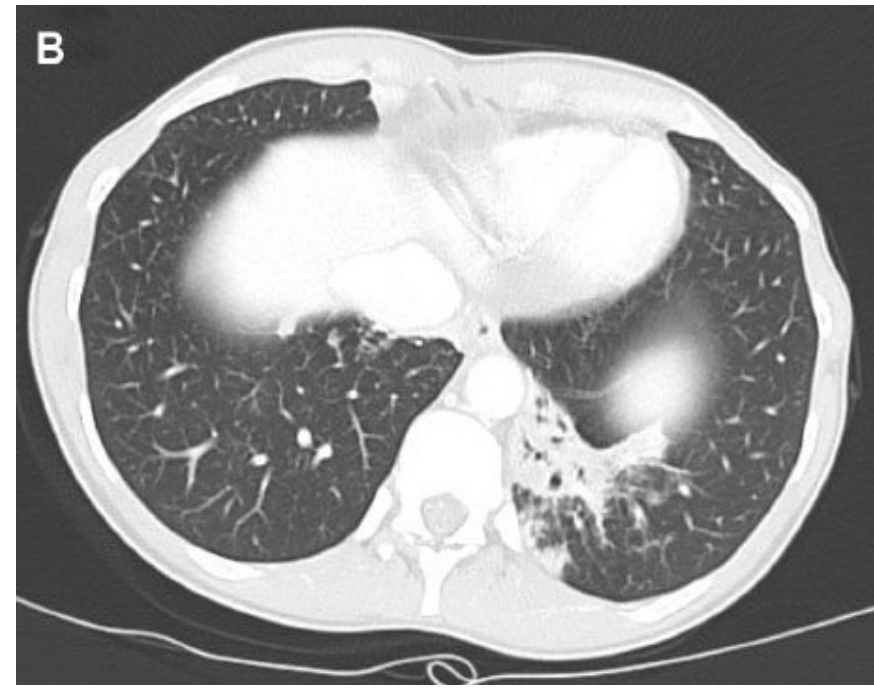

Рис. 2. Томография - очаг актиномикоза в нижней доли легкого

При инфицировании актиномицетами молочной железы в клинической картине обращает на себя внимание образование рецидивных свищей, наличие плотного инфильтрата на фоне отсутствия сильных болей.

Деструктивные изменения в костной ткани ребер и грудины имеют характерные для актиномикоза черты: чередование участков остеосклероза и остеолизиса, округлые дефекты в виде "сот" или “пробойниковых отверстий" и др.

Диагностировать торакальный актиномикоз достаточно проблематично, т.к. на начальной стадии заболевания отсутствуют какие-либо специфические проявления актиномикоза. Зачастую диагноз выставляется только при лабораторном исследовании мокроты на наличие друз грибка.

При бронхоскопии: эндобронхит, ригидность и деформация бронхов, вплоть до развития симптома «ампутация бронха». На рентгенограммах - усиление легочного рисунка, интенсивная инфильтрация легочной ткани, эмфизема, фиброз в прикорневой зоне.

При фистулографии определяются разветвленные свищевые ходы. Рентгенологически вначале выявляется снижение прозрачности легочной ткани, затем наоборот плотность усиливается, тень становится мраморной за счет множества просветлений, воспалительный очаг неоднородной структуры с полицикличными неровными контурами иногда соединяется «дорожкой» с корнем легкого, часто поражается плевра. В актиномикотический конгломерат постепенно вовлекаются главные бронхи (рис. 1, 2). 
Подтвердить диагноз актиномикоза поможет гистологическое исследование при взятии материала при инвазивном вмешательстве.

Лечение торакального актиномикоза предполагает комплексную терапию. Причем необходимо отметить, что ранняя диагностика и своевременно начатое лечение дает благоприятный исход.

Комплексная терапия включает в себя использование антибактериальных препаратов, сульфаниламидов, иммунотерапию, общеукрепляющие средства, физиолечение, хирургические вмешательства, иногда по показаниям проводят дезинтоксикационную терапию.

При применении антибактериальных препаратов предпочтение отдается антибиотикам пенициллинового ряда. Можно назначать тетрациклины, аминогликозиды и цефалоспорины. Длительность применения от 10 дней до 2 недель в максимальных дозах.

Использование сульфаниламидных препаратов дает очень хороший противовоспалительный эффект.

Для воздействия на иммунную систему с целью стимуляции продукции антител к различным возбудителям инфекции и повышению резистентности организма наиболее эффективно использовать актинолизат. Препарат вводят внутримышечно 3 раза в неделю: детям до 3 лет по 0,1 мл/ кг, от 3 до 14 лет — по 2 мл, после 14 лет - по 3 мл. Продолжительность курса - 20-25 инъекций.перерыв между курсами - 1 мес. Число курсов (от 2 до 6) зависит от формы и тяжести заболевания. Через 1 месяц после клинического выздоровления для предупреждения рецидива проводят профилактический курс (5-15 инъекций) [2].

Текущие рекомендации для антибиотикотерапии актиномикоза следующие [3]:

- амоксициллин + клавулановая кислота:
1 неделя - 2 г 3 раза в день амоксициллина + 19. 0.2 г 3 раза в день клавулановой кислоты;

- 2-4 неделя - 1 г 3 раза в день амоксициллина +

0,1 г 3 раза в день клавулановой кислоты;

- Актинолизат Змл внутримышечно 2 раза в неделю - 25 инъекций,

через 1 месяц курс повторить, число инъекций сокращается до 20.

- Местное воздействие УФО на рану.

В остром периоде чаще всего хирургическое лечение заключается в дренировании очага с последующим применением противовосполительной, иммунной, антибактериальной терапии.

При актиномикозе легких и колонизации легочных каверн актиномицетами проводятся лобэктомия, иногда с резекцией ребер, вскрытие и дренирование гнойных полостей, каверн и очагов распада. В случае актиномикоза подмышечных и паховых областей, развившегося на фоне хронического гнойного гидраденита, очаги поражения иссекают, по возможности единым блоком, в пределах визуально здоровых тканей [1].

При развитии актиномикотического процесса в молочной железе производят секторальное иссечение очагов актиномикоза с предварительным прокрашиванием свищевых ходов [1].

В послеоперационном периоде продолжают противовоспалительную и иммуномодулирующую терапию актинолизатом, по показаниям проводят гемотрансфузии и физиопроцедуры, ежедневно делают перевязки. Швы снимают на 8-10-й день. Прогноз более благоприятный, если лечение начато на ранних стадиях заболевания на фоне адекватной иммунотерапии актинолизатом [1].

\section{ЛИТЕРАТУРА}

1. Бурова С. А. Торакальный актиномикоз. Пульмонология и аллергология. - 2012.— № 3.— С. 2-4.

2. Бурова С.А., Федюкина М. Ю., Эмирасланов Ф. Л., Яковлев А. Б. и другие. Актинолизат — эффективное иммуномодулирующее средство с противовоспалительным действием для лечения разнообразных форм гнойно-воспалительных бактериальных и грибковых заболеваний. Материалы научно-практической конференции «Импортозамещение, доступная медицинская помощь и равные возможности в дерматологии».— M., 2017.— C. 112-115.

3. Яшнов А.А., Лобанов С. Л., Коновалова 0. Г., Яшнова Н. Б., Мантуленко Л. В., Черешнева 0. И. Актиномикоз человека современное представление // Современная наука: актуальные проблемы теории и практики. Серия «Естественные и технические науки».— 2018. — № 4. — c. $196-201$.

( ) Коновалова Ольга Геннадьевна, Яшнов Алексей Александрович ( alexyashnov@mail.ru ),

Ханина Юлия Сергеевна, Яшнова Надежда Борисовна, Бурцева Мария Александровна.

Журнал «Современная наука: актуальные проблемы теории и практики» 